\title{
RESEARCH
}

Open Access

\section{Cell-free oxidized hemoglobin drives reactive oxygen species production and pro-inflammation in an immature primary rat mixed glial cell culture}

Alex Adusei Agyemang', Suvi Vallius Kvist', Nathan Brinkman², Thomas Gentinetta ${ }^{3}$, Miriam Illa ${ }^{4}$, Niklas Ortenlöf', Bo Holmqvist ${ }^{5}$, David Ley ${ }^{1}$ and Magnus Gram ${ }^{1 *}$ (D

\begin{abstract}
Background: Germinal matrix intraventricular hemorrhage (GM-IVH) is associated with deposition of redox active cellfree hemoglobin $(\mathrm{Hb})$, derived from hemorrhagic cerebrospinal fluid (CSF), in the cerebrum and cerebellum. In a recent study, using a preterm rabbit pup model of IVH, intraventricularly administered haptoglobin ( $\mathrm{Hp})$, a cell-free $\mathrm{Hb}$ scavenger, partially reversed the damaging effects observed following IVH. Together, this suggests that cell-free $\mathrm{Hb}$ is central in the pathophysiology of the injury to the immature brain following GM-IVH. An increased understanding of the causal pathways and metabolites involved in eliciting the damaging response following hemorrhage is essential for the continued development and implementation of neuroprotective treatments of GM-IVH in preterm infant.

Methods: We exposed immature primary rat mixed glial cells to hemorrhagic CSF obtained from preterm human infants with IVH (containing a mixture of $\mathrm{Hb}$-metabolites) or to a range of pure $\mathrm{Hb}$-metabolites, incl. oxidized $\mathrm{Hb}$ (mainly metHb with iron in $\mathrm{Fe}^{3+}$ ), oxyHb (mainly $\mathrm{Fe}^{2+}$ ), or low equivalents of heme, with or without co-administration with human $\mathrm{Hp}$ (a mixture of isotype 2-2/2-1). Following exposure, cellular response, reactive oxygen species (ROS) generation, secretion and expression of pro-inflammatory cytokines and oxidative markers were evaluated.
\end{abstract}

Results: Exposure of the glial cells to hemorrhagic CSF as well as oxidized $\mathrm{Hb}$, but not oxyHb, resulted in a significantly increased rate of ROS production that positively correlated with the rate of production of pro-inflammatory and oxidative markers. Congruently, exposure to oxidized $\mathrm{Hb}$ caused a disintegration of the polygonal cytoskeletal structure of the glial cells in addition to upregulation of F-actin proteins in microglial cells. Co-administration of Hp partially reversed the damaging response of hemorrhagic CSF and oxidized $\mathrm{Hb}$.

Conclusion: Exposure of mixed glial cells to oxidized $\mathrm{Hb}$ initiates a pro-inflammatory and oxidative response with cytoskeletal disintegration. Early administration of $\mathrm{Hp}$, aiming to minimize the spontaneous autoxidation of cell-free $\mathrm{oxyHb}$ and liberation of heme, may provide a therapeutic benefit in preterm infant with GM-IVH.

Keywords: Intraventricular hemorrhage, Hemoglobin metabolites, Haptoglobin, Hemorrhagic cerebrospinal fluid, Mixed glial cells, Redox

\footnotetext{
* Correspondence: magnus.gram@med.lu.se

'Lund University, Department of Clinical Sciences Lund, Pediatrics, Lund, Sweden

Full list of author information is available at the end of the article
}

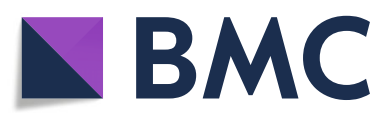

(- The Author(s). 2021 Open Access This article is licensed under a Creative Commons Attribution 4.0 International License, which permits use, sharing, adaptation, distribution and reproduction in any medium or format, as long as you give appropriate credit to the original author(s) and the source, provide a link to the Creative Commons licence, and indicate if changes were made. The images or other third party material in this article are included in the article's Creative Commons licence, unless indicated otherwise in a credit line to the material. If material is not included in the article's Creative Commons licence and your intended use is not permitted by statutory regulation or exceeds the permitted use, you will need to obtain permission directly from the copyright holder. To view a copy of this licence, visit http://creativecommons.org/licenses/by/4.0/ The Creative Commons Public Domain Dedication waiver (http://creativecommons.org/publicdomain/zero/1.0/) applies to the data made available in this article, unless otherwise stated in a credit line to the data. 


\section{Background}

Germinal matrix intraventricular hemorrhage (GM-IVH) in preterm infants is associated with a high incidence of neurodevelopmental impairment leading to cerebral palsy and intellectual disability [1]. Cerebro-cerebellar deposition of the redox active cell-free hemoglobin $(\mathrm{Hb})$, derived from hemorrhagic cerebrospinal fluid (CSF) in the intraventricular space, has been described to be central in the pathophysiology of brain injury following GM-IVH in preterm infants [2, 3]. Following hemolysis, released cell-free $\mathrm{Hb}$ within the intraventricular space is spontaneously autoxidized from oxyHb $\left(\mathrm{Fe}^{2+}-\mathrm{Hb}\right)$ to metHb $\left(\mathrm{Fe}^{3+}-\mathrm{Hb}\right)$. Further downstream reactions can lead to the formation of highly oxidized ferryl $\mathrm{Hb}\left(\mathrm{Fe}^{4+}\right.$ $\mathrm{Hb})$, globin radicals, free heme and heme polymers [4-7]. The subsequent degradation results in the generation of bilirubin, carbon monoxide, and free iron. Cell-free $\mathrm{Hb}$ and its metabolites are known to be initiators of cytotoxic, oxidative, pro-inflammatory, and apoptotic events inducing tissue damage [8-12]. Although published data clearly describe the involvement of $\mathrm{Hb}$ in the development of brain damage [4-7], a limitation of the studies conducted up to date has been the inability to characterize the importance of the different $\mathrm{Hb}$-metabolites responsible for the observed damage.

We have previously shown that accumulated levels of metHb correlated with levels of tumor necrosis factor alpha (TNF $\alpha)$ protein in intraventricular CSF following preterm IVH [13]. Interestingly, and somewhat contradictory, some studies have actually reported beneficial effects following exposure to cell-free $\mathrm{Hb}$. For instance, Amri et al. [14] report that oxyHb in low concentrations protects cortical astroglial cell cultures by inhibiting oxidative stress and caspase activation following exposure to hydrogen peroxide. The protective effect of oxyHb was linked to its ability to induce the protein kinase A and $\mathrm{C}$ signal transduction pathways whilst reducing nuclear factor kappa beta (NFKB) activation [14]. An increased understanding and appreciation of the role of different Hb-metabolites, as well as triggered causal pathways, is vital in order to develop and implement neuroprotective strategies and deducing a possible therapeutic window for intervention with $\mathrm{Hb}$-metabolite scavengers.

Irrespective of the known importance of paracrine signaling between glial cells in brain abnormalities, previous in vitro studies on cerebral hemorrhage have, to the best of our knowledge, focused on single cell types [15-17]. Although a single cell culture will delineate the specific response of a cell type, it may not be a true reflection of the in vivo setting and hence this needs to be addressed.

In this study, we hypothesize that production of reactive oxygen species (ROS) by Hb-metabolites, is central to the detrimental pathways following preterm IVH. Results show that in vitro exposure of an immature primary rat mixed glial cell culture to oxidized $\mathrm{Hb}$, rather than $о x y H b$, led to a similar damaging response as exposure to hemorrhagic CSF. Furthermore, the rate of ROS production was found to positively correlate with that of pro-inflammatory and oxidative markers. Congruently, oxidized $\mathrm{Hb}$ caused structural disintegration and morphological changes in the mixed glia cells. Interestingly, co-administration with haptoglobin ( $\mathrm{Hp})$, a cell-free $\mathrm{Hb}$ scavenger, could only partially reverse the damaging response of hemorrhagic CSF and of oxidized $\mathrm{Hb}$.

\section{Materials and methods}

\section{Cell culture}

The use of animals was approved by the Swedish Animal Ethics Committee in Lund. Primary mixed glial cell cultures, comprising microglia, astrocytes, and oligodendrocytes, were prepared from postnatal day 1 Sprague Dawley rats (Janvier, Le Genest-Saint-Isle, France). Briefly, cerebral hemispheres were dissected in ice-cold Hank's balanced salt solution (HBSS, Thermo Fisher, Waltham, MA, USA) in order to carefully remove the cerebellum, eyes, and meninges. The cerebrum was then cut in two cortices to remove all seen vessels. The cerebrum was subsequently minced, vessels removed and the cell mass transferred to a $15 \mathrm{ml}$ tube containing HBSS and centrifuged at $300 \times g$ for $5 \mathrm{~min}$ at room temperature (RT). The supernatant was removed and pre-heated complete culture medium (Dulbecco's modified eagle medium, DMEM, with glutamine, $4.5 \mathrm{~g}$ L-glucose $+10 \%$ fetal bovine serum (FBS), $1 \%$ penicillin and streptomycin, Thermo Fisher) was added. Using a fire-polished glass pipette, a homogenous cell suspension was obtained by pipetting up and down repeatedly. The cell suspension was then directly filtrated through a $40 \mu \mathrm{m}$ mesh and resuspended in pre-heated complete culture medium. Cells were then seeded in poly-D-lysine (Sigma Aldrich, Summit drive Burlington, MA, USA) coated multi-well plates, flasks or on cover slips (for immunocytochemistry, ICC, see further description below). The glial culture, as visualized microscopically, was a pure heterogenic mixture, largely made of astrocytes and fewer proportions of microglia and oligodendrocytes.

\section{Preparation of oxyHb, oxidized $\mathrm{Hb}$, and heme}

Human oxyHb was purified as previously described [18] from human blood of healthy subjects. The use of human blood was approved by the ethical committee review board for studies in human subjects at Lund University, Lund, Sweden. Oxidized $\mathrm{Hb}$ (containing a mixture of $\mathrm{Hb}$-metabolites with mainly $\mathrm{Fe}^{3+}$ and some proportion of $\mathrm{Fe}^{4+}$, free heme, and iron) was prepared by incubating the purified oxyHb solution at $37^{\circ} \mathrm{C}$ for $72 \mathrm{~h}$ 
(as described by Gram et al. [11]). The proportion of oxyHb to metHb $\left(\mathrm{Fe}^{3+}-\mathrm{Hb}\right)$ was determined by a spectrophotometric scan coupled with the equation as described by Winterbourn [18]. The purified $\mathrm{Hb}$ from human blood was found to contain in proportion 99\% oxyHb to $1 \%$ oxidized $\mathrm{Hb}$, and the subsequently prepared oxidized $\mathrm{Hb}$ solution had in proportion $70 \%$ oxidized $\mathrm{Hb}$ species to $30 \%$ oxyHb. Heme (Ferriprotoporphyrin IX chloride) was purchased from Porphyrin Products Inc. (Logan, UT, USA), and a 10-mM stock solution was prepared using dimethyl sulfoxide (Sigma Aldrich). All $\mathrm{Hb}$ solutions were purified from endotoxin contamination using the endotoxin-removing product EndoTrap as described by the manufacturer (Hyglos $\mathrm{GmbH}$, Bernried am Starnberger See, Germany).

\section{Hemorrhagic CSF from preterm infants with GM-IVH}

Hemorrhagic CSF was sampled from preterm infants (gestational age at birth 25-28 weeks) after detection of GM-IVH, by spinal tap or ventricular reservoir puncture according to clinical routine in the neonatal unit at Lund University Hospital, Lund, Sweden. Immediately after sampling, the CSF was centrifuged at $2000 \times g, 20^{\circ} \mathrm{C}$ for $10 \mathrm{~min}$, pooled and the proportion of oxyHb and metHb was determined as described above. Samples were stored at $-80^{\circ} \mathrm{C}$ until further use, as described below. The sampling was performed following written consent from the parents, and the study was approved by the ethical committee review board for studies in human subjects at Lund University, Lund, Sweden.

\section{Experimental design}

Mixed glial cells were grown in culture medium containing $10 \%$ FBS until day 5-7, at what point all experiments were performed. Complete medium was removed and cells were incubated at $37^{\circ} \mathrm{C}$ with any of the following component (i) hemorrhagic CSF from human preterm infants with IVH (containing a mixture of $\mathrm{Hb}$-metabolites), (ii) oxyHb, (iii) oxidized $\mathrm{Hb}$, or (iv) heme. The components were substituted in fresh serum-free culture medium, containing DMEM supplemented with $2 \%$ of antioxidant-free B-27 supplement (Thermo Fisher), prior to their respective addition to the cells. In addition, co-administration with human Hp (a mixture of isotype 2-2/2-1, CSL Behring, Kankakee, IL, USA) or NFKB inhibitor VI benzoxathiole compound (Abcam, Cambridge, UK) dissolved in DMSO was included in some of the experiments. Fresh serum-free culture medium, supplemented with $2 \%$ of antioxidant-free B-27 supplement served as the control condition (referred to as "control") in all the experiments. Details of exposures and incubations are further described in respective figure legends.

After incubation, cell culture medium was collected (for protein analysis) and cells analyzed (for ROS production) or harvest (for RNA extraction and mRNA expression analysis) as described below.

\section{Measurement of intracellular ROS formation}

ROS were detected by measuring the fluorescence of 2, 7dichlorofluorescein (DCF), which is derived from the deacetylation and oxidation of the non-fluorescent compound DCFH2-DA, as described by the manufacturer (Abcam, Cambridge, UK). At the end of the exposure period, cells were washed twice with phosphate-buffered saline (PBS) and then incubated with $25 \mu \mathrm{M}$ DCFH2-DA for $45 \mathrm{~min}$ at $37^{\circ} \mathrm{C}$ in the dark. Fluorescence was measured with excitation at $483 \mathrm{~nm}$ and emission at $535 \mathrm{~nm}$ using a fluorescence microplate reader (VICTOR 1420 multilabel plate reader, Perkin Elmer, Waltham, MA, USA).

\section{RNA isolation and real-time PCR}

RNA was isolated from mixed glia cell cultures utilizing the RNeasy Micro Kit (Qiagen, Alden, Germany) with purity and concentration confirmed using a NanoDrop ND-1000 spectrophotometer (Saveen \& Werner AB, Limhamn, Sweden). The optical density ratio (at $260 \mathrm{~nm} / 280 \mathrm{~nm}$ ) of extracted RNA samples was always approximately 2.0. One microgram of RNA was used as a template for reverse transcriptase reactions using the iScript RT kit (Bio-Rad, Hercules, CA, USA). cDNA was mixed with iTaq Universal SYBR Green super mix (Bio-Rad). Amplification was performed as described by the manufacturer (Bio-Rad) for 40 cycles in a CFX Connect thermal cycler (Bio-Rad), and data were analyzed using CFX Maestro Software (Bio-Rad). The $2^{-\Delta \Delta C T}$ method was used to determine fold expression with normalization to glyceraldehyde 3-phosphate dehydrogenase (GAPDH) expression and control samples from untreated cells. Primers (Primer PCR assay from Bio-Rad) for the following genes, inducible nitric oxide synthase (iNOS), heme oxygenase-1 (HO-1), TNF $\alpha$, and superoxide dismutase 2 (SOD2), were analyzed.

NFKB Signaling Pathway (PARN-0252D, Qiagen, Maryland, USA) and Apoptotic Pathway (PARN-0122D, Qiagen, Maryland, USA) array were performed on all experimental conditions by using $1 \mu \mathrm{g}$ of pooled RNA as template for reverse transcriptase reactions using the $\mathrm{RT}^{2}$ First Strand Kit (Qiagen). cDNA was mixed with $\mathrm{RT}^{2}$ SYBR Green qPCR Master mix (Qiagen). Amplification was performed as described by the manufacturer (Bio-Rad) for 40 cycles in a CFX Connect thermal cycler (Bio-Rad), and data were analyzed using CFX Maestro Software (Bio-Rad). Normalization and determination of fold change expression for the panel of genes was done on the Qiagen Data analysis center platform.

\section{Immunocytochemistry}

Immunolabeling of mixed glia cells was performed to investigate the changes in structural morphology, reactivity, and activity of the glia cell types following exposure 
to the respective experimental condition as indicated in figure legends.

The ICC protocol was carried accordingly. Following exposure, experimental culture medium was removed from wells. Cells were then washed once with PBS and subsequently fixed for $15 \mathrm{~min}$ at RT with $4 \%$ paraformaldehyde (PFA, in 0.1 M PBS, pH 7.4). PFA solution was removed, cells were washed $3 \times$ with $\mathrm{PBS}$ and then permeabilized by incubation with $0.1 \%$ Triton X-100 in PBS for $10 \mathrm{~min}$ at RT. Following washing $3 \times$ with PBS, the cells were blocked with $2 \%$ bovine serum albumin (BSA, Sigma Aldrich, diluted in PBS) for $1 \mathrm{~h}$ at RT. Incubation with primary antibodies (diluted in $2 \%$ BSA in PBS) was performed overnight at $+4{ }^{\circ} \mathrm{C}$. The primary antibodies used were as follows: Ibal (ionized calciumbinding adaptor molecule 1, diluted 1:500, Wako, Neuss, Germany) and phalloidin (diluted 1:900, Thermo Fisher). Following incubation, cells were washed $3 \times 10 \mathrm{~min}$ with $2 \%$ BSA in PBS, followed by incubation with respective secondary antibody for $30 \mathrm{~min}$ at RT diluted in $2 \%$ BSA in PBS. The secondary antibodies were as follows: antirabbit antibody conjugated with Alexa Fluor 647 (AF647, Life Technologies, Eugene, OR, USA) and actin conjugated with Texas Red (Thermo Fisher). Cells were subsequently washed $3 \times 10 \mathrm{~min}$ with $\mathrm{PBS}$ followed by nuclear staining, using Hoechst stain (diluted 1:10,000 in PBS, Life Technologies), $5 \mathrm{~min}$ at RT. After incubation, cells were further washed $3 \times$ with PBS and mounted with mounting media to microscopic slide. Sections were examined and photographed using a Zeiss system (Carl Zeiss microscopy, Thornwood, NY, USA). Representative images were further evaluated using ImageJ and image plates generated with Photoshop (Adobe, San Jose, CA, USA).

\section{ELISA analysis of cell culture medium}

The concentration of chemokine ligand 2 (CCL2), chemokine ligand 5 (CCL5), and lipocalin-2, secreted into the cell culture medium of the mixed glial cells following exposure to the respective experimental conditions (as indicated in the figure legends), were determined using the Quantikine (CCL2, CCL5) and DuoSet (lipocalin-2) ELISA Development Kits (R\&D Systems, Minneapolis, Minnesota, USA). The analysis was performed according to the instructions from the manufacturer.

\section{$\mathrm{Hp}-\mathrm{Hb}$ binding studies}

Binding affinity studies were performed in order to ascertain binding of the cell-free Hb-metabolites in the cell culture experiment to the added $\mathrm{Hp}$. Binding kinetics were performed using amine-reactive biosensors (Pall, ForteBio, Cat\#: 18-5092) in an Octet Red 96 (Pall, ForteBio). First, the biosensor tips were equilibrated in water for $10 \mathrm{~min}$. After recording a baseline, $\mathrm{Hp}$ was immobilized on biosensors in acetate buffer ( $\mathrm{pH}$ 5.0) for 600 s. For the association step, either oxyHb or metHb was twofold serially diluted $(0,0.94,1.88,3.75,7.50,15$, and $30 \mathrm{nM})$. As a control, the binding of $\mathrm{Hb}$ in the absence of $\mathrm{Hp}$ was measured. Raw data were analyzed by Octet System Data analysis version 9.0 (Pall, ForteBio) and fitted to a global 1:1 kinetic model to determine $k_{\mathrm{on}}, k_{\mathrm{off}}$, and $K_{D}$.

\section{Protein extraction and analysis}

Following exposure to oxidized $\mathrm{Hb}$, with or without the NFKB inhibitor VI benzoxathiole compound, mixed glial cells were washed with PBS, scraped, and transferred to a centrifugation tube. Following centrifugation $(300 \times g$, 6 $\mathrm{min}$ ), the pellet was resuspended in $500 \mu \mathrm{l}$ complete Cell Extraction Buffer (Invitrogen, UK), containing a protease inhibitor cocktail (Roche, Mannheim, Germany), incubated $30 \mathrm{~min}$ on ice and centrifuged $(3000 \times g, 10 \mathrm{~min}$, $4{ }^{\circ} \mathrm{C}$ ). The supernatant (containing the cytosolic fraction was transferred to a new tube). The pellet was resuspended in $50 \mu \mathrm{l}$ complete Cell Extraction Buffer (as described above) and incubated for $15 \mathrm{~min}$ on ice, followed by centrifugation $\left(14,000 \times g, 30 \mathrm{~min}, 4^{\circ} \mathrm{C}\right)$. The supernatant (containing the nuclear fraction) was transferred to a new tube.

Protein concentrations were quantified in both the cytosolic and the nuclear fraction using the BCA protein assay kit according to instructions from the manufacturer (Thermo Scientific, Waltham, MA, USA). Absorbance was measured at $550 \mathrm{~nm}$ (VICTOR 1420 multilabel plate reader, Perkin Elmer). The cytosolic and nuclear fraction was stored at $-80^{\circ} \mathrm{C}$ until further analysis.

\section{Western blot analysis of NFKB pathway activation}

SDS-PAGE was performed with pre-cast stain-free 420\% gels (Mini-Protean TGX, Bio-Rad). Precision Plus Protein All Blue Prestained Protein Standards were used for size determination of proteins (Bio-Rad). After transfer to polyvinylidene difluoride (PVDF) membranes by electroblotting (Transblot ${ }^{\circ}$ Turbo, Bio-Rad), membranes were incubated in blocking solution (5\% non-fat dry milk (Bio-Rad) in PBS containing 0.05\% Tween, PBS-T), followed by a primary rabbit anti-p 65 antibody $(0.5 \mu \mathrm{g} /$ $\mathrm{ml}$, Abcam, diluted in 5\% non-fat dry milk in PBS-T). Swine anti-rabbit IgG horseradish peroxidase (HRP, Dako, Glostrup, Denmark), diluted 1:1700 in 1\% non-fat dry milk in PBS-T, was used as secondary antibody. Signals from HRP-conjugates were detected using Clarity Western ECL Substrate (Bio-Rad). Re-blotting against $\beta$ actin (cytosolic fraction) or Lamin B1 (nuclear fraction) were performed by using a primary mouse anti-actin antibody (Abcam, diluted 1:10,000 in 1\% non-fat dry milk in PBS-T) or rabbit anti-Lamin B1 antibody (Abcam, diluted 1:10,000 in 5\% non-fat dry milk in PBS- 
T). Goat anti-mouse IgG-Alexa Fluor 488 (Invitrogen, diluted 1:5000 in 1\% non-fat dry milk in PBS-T) or swine anti-rabbit IgG-HRP (Dako, diluted 1:1700 in 1\% non-fat dry milk in PBS-T) were used as secondary antibodies. Signals from HRP-conjugates were detected using Clarity Western ECL Substrate (Bio-Rad). Membranes and gels were imaged and analyzed using the ChemiDoc $^{\text {tux }}$ MP System (Bio-Rad).

\section{Statistics}

Statistical analysis was performed with IBM SPSS Statistics version 25 (Armonk, NY, USA). Results are presented as medians (ranges) and displayed as box plots or bar graphs. Comparisons between unrelated groups were performed with the Mann-Whitney $U$ test as appropriate. Comparisons between multiple groups were made using the Kruskal-Wallis test followed by pairwise comparison with significance values adjusted for multiple comparisons. $P$ values $<0.05$ were considered significant.

\section{Results}

Cellular response following exposure to hemorrhagic CSF Immunofluorescent (IF) labeling of the glial cellular types was evaluated following a $24 \mathrm{~h}$ exposure to hemorrhagic CSF and revealed a change in morphology of Iba1 microglia cells from a rod shape (Fig. 1b) to an activated round like flat shape (Fig. 1f). Furthermore, labeled F-actin showed an intermediate change in the polygonal organization of the cytoskeletal structure of the glial cells following exposure to hemorrhagic CSF (Fig. 1g) as compared to control cells (Fig. 1c). These observations were accompanied by a significant induction of ROS production, TNF $\alpha$ and

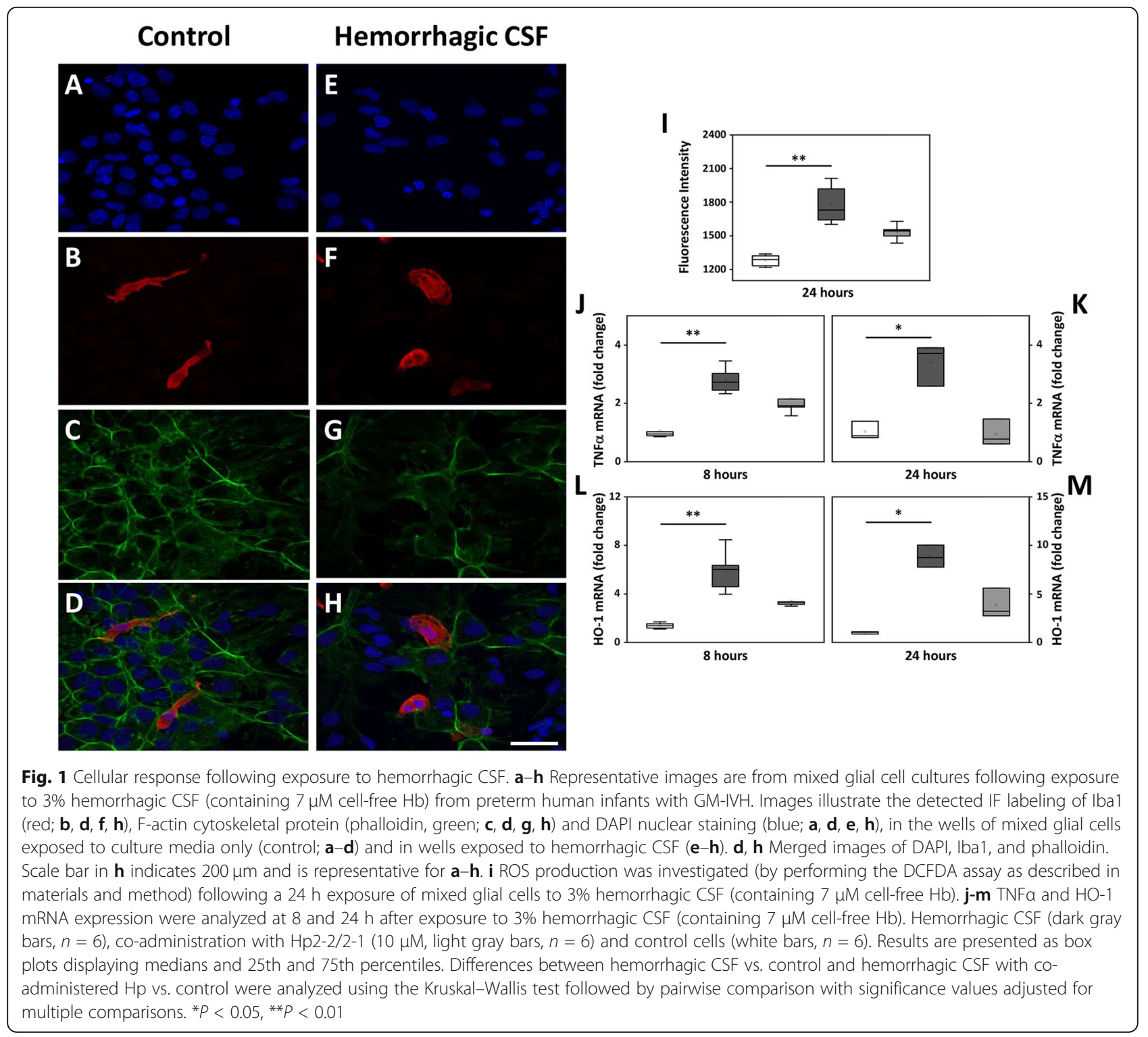


HO-1 mRNA expression (Fig. 1i-m) following exposure to hemorrhagic CSF for 8 and 24h. Furthermore, the changes were found to be dose-dependent (not shown). Co-administration of $\mathrm{Hp}$, a cell-free $\mathrm{Hb}$ scavenger, partially reduced the observed effects (Fig. 1i$\mathrm{m})$, in some cases down to the levels of control cells (HO-1 at $8 \mathrm{~h}$ and TNF $\alpha$ and $\mathrm{HO}-1$ at $24 \mathrm{~h}$ ).

Cellular response following exposure to pure $\mathrm{Hb}$-metabolites Iba1 immunoreactivity was investigated to evaluate microglial response following $24 \mathrm{~h}$ exposure to pure $\mathrm{Hb}$ metabolites (Fig. 2). All metabolites (oxyHb, oxidized $\mathrm{Hb}$ and heme) caused a change in the morphology of microglia cells, from rod shape (control, Fig. 2b) to a round amoeboid like shape (Fig. 2f, j, n). In addition, oxidized $\mathrm{Hb}$, but not oxyHb nor heme, caused a disintegration of the polygonal cytoskeletal structure of the glial cells, as revealed by F-actin labeling (Fig. 2c, g, k, o). Furthermore, an upregulation of $\mathrm{F}$-actin proteins in microglial cells, a marker of microglial metamorphosis, motility, activation, and cytokinesis was observed following exposure to oxidized $\mathrm{Hb}$ (Fig. 2k). Congruently, exposure to oxidized $\mathrm{Hb}$ but not oxyHb nor heme (heme data not shown) for $24 \mathrm{~h}$ caused a significant upregulated mRNA expression of

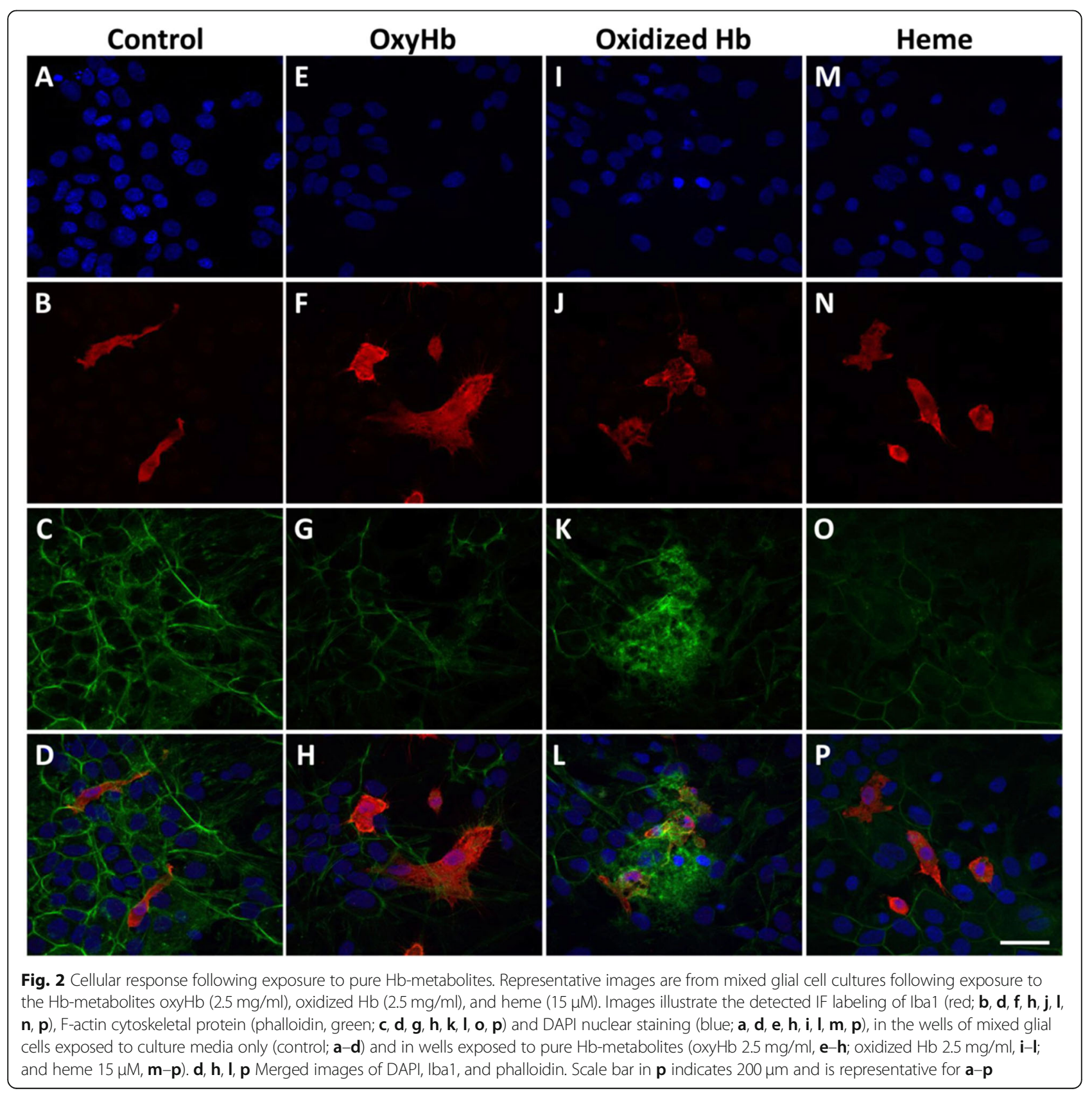



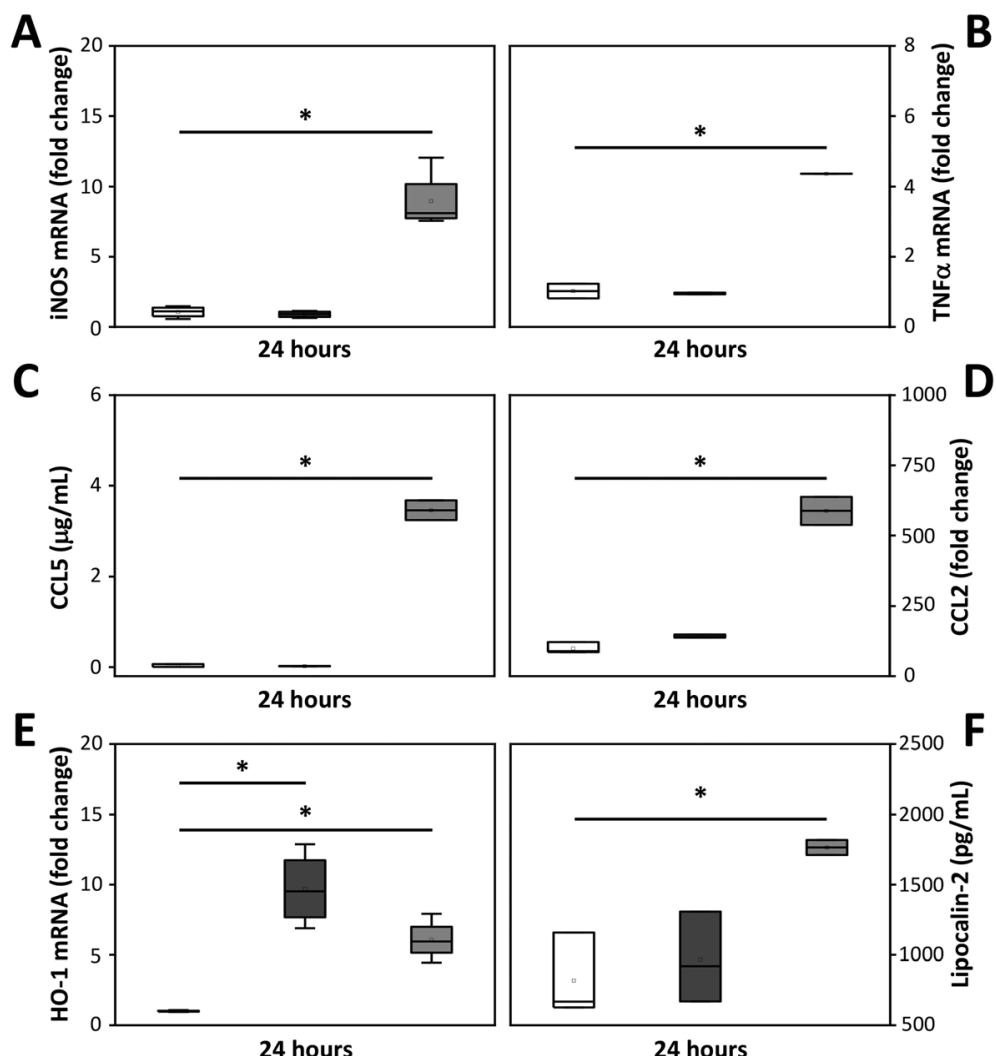

Fig. 3 Oxidized $\mathrm{Hb}$ induces a pro-inflammatory response. mRNA expression and protein secretion of pro-inflammatory and oxidative stress markers, iNOS (a), TNFa (b), CCL5 (c), CCL2 (d), HO-1 (e), and lipocalin-2 (f) were investigated following exposure of mixed glial cell cultures to pure $\mathrm{Hb}$-metabolites (oxyHb $2.5 \mathrm{mg} / \mathrm{ml}$, dark gray bar, $n=4$; oxidized Hb $2.5 \mathrm{mg} / \mathrm{ml}$, light gray bar, $n=4$ ) or culture medium only (control, white bar, $n=4$ ). Results are presented as box plots displaying medians and 25th and 75th percentiles. Differences between oxyHb vs. control, oxidized $\mathrm{Hb}$ vs control, and oxidized $\mathrm{Hb}$ vs oxyHb were analyzed using the Kruskal-Wallis test followed by pairwise comparison with significance values adjusted for multiple comparisons. ${ }^{*} P<0.05$

iNOS, TNFa, and HO-1 (Fig. 3a, b, e) as well as an increased protein secretion into the culture medium of CCL5, CCL2, and lipocalin-2 (Fig. 3c, d, f).

\section{Dose-dependent effect of oxidized $\mathrm{Hb}$}

The mixed glial cell culture was exposed to different concentrations of the oxidized $\mathrm{Hb}$ solution for $24 \mathrm{~h}$. Analysis revealed a significant dose-dependent increase of ROS production, mRNA expression of iNOS, and protein secretion of the pro-inflammatory cytokines CCL2 and CCL5 (Fig. 4a-d). In line with above described data, exposure to oxyHb did not result in an increased iNOS mRNA expression nor in an increased secretion of pro-inflammatory cytokines (not shown).

\section{Effect of $\mathrm{Hp}$ on the damage induced by oxidized $\mathrm{Hb}$}

The effect of $\mathrm{Hp}$, a cell-free $\mathrm{Hb}$ scavenger, to reduce or inhibit the damaging response following exposure of the mixed glial cell culture to oxidized $\mathrm{Hb}$ was investigated by co-administration with $\mathrm{Hp}$ (in a 1:1 molar ratio, where all cell-free $\mathrm{Hb}$ are bound by $\mathrm{Hp}$ ). A significant reduction on the levels of ROS production, and a tendency towards reduction on the levels of mRNA expression of HO-1 and SOD2 were observed following addition of $\mathrm{Hp}$. Of note, $\mathrm{Hp}$ displayed similar effects on lower levels of oxidized $\mathrm{Hb}$, as long as a 1:1 molar ratio or surplus of $\mathrm{Hp}$ was added (not shown). Contrarily, no reduction in induced mRNA expression of iNOS by oxidized $\mathrm{Hb}$ was observed following co-administration with Hp (Fig. 5a-d).

\section{$\mathrm{Hp}$ binding to $\mathrm{Hb}$-metabolites}

To ascertain whether the partially protective effect of $\mathrm{Hp}$, on oxidized $\mathrm{Hb}$-induced response, was due to lack of a strong binding of the oxidized $\mathrm{Hb}$, binding studies were performed with the respective Hb-metabolites. A sensogram showed that the added $\mathrm{Hp}$ bound well to both the oxyHb and metHb with a similar binding affinity. The binding curves for the response over time for the different metabolites showed that both oxyHb and metHb bound strongly and irreversibly to the added $\mathrm{Hp}$ (Table 1 and Additional file 1 and 2). 

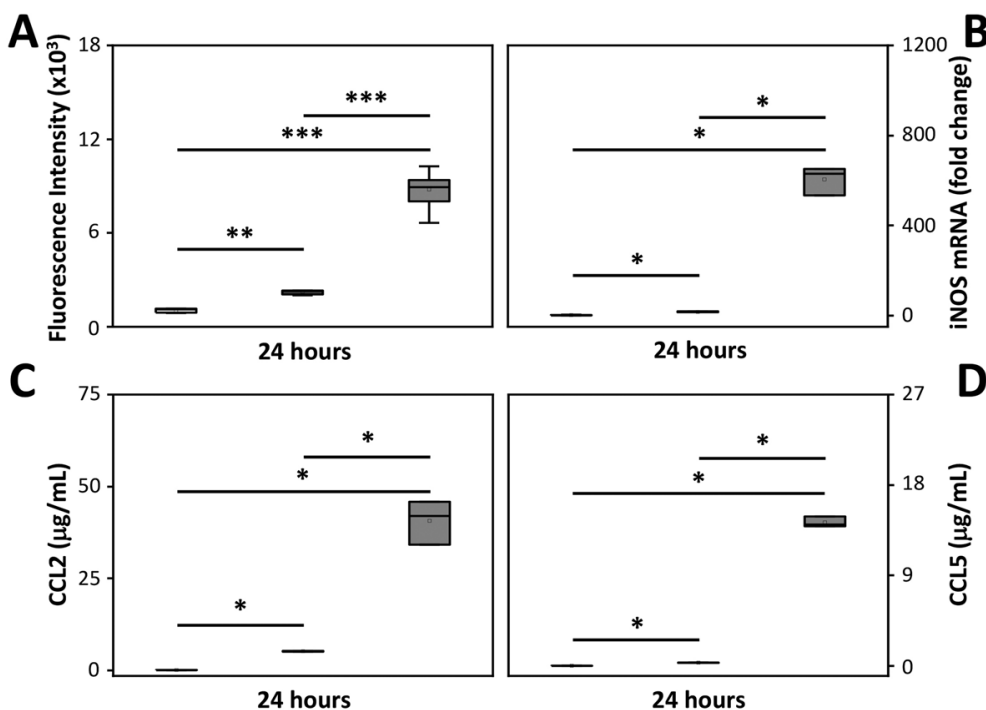

Fig. 4 Dose-dependent effect of oxidized Hb. Mixed glial cells were exposed to increasing concentration of oxidized Hb $(5 \mathrm{mg} / \mathrm{ml}$, dark grey bars, $n=6 ; 10 \mathrm{mg} / \mathrm{ml}$, light grey bars, $n=6$ ) or culture medium only (control, white bar, $n=6)$ for $24 \mathrm{~h}$. Subsequently, ROS production (a), mRNA expression of iNOS (b) and protein secretion of CCL2 (c) and CCL5 (d) were analyzed. Results are presented as box plots displaying medians and 25th and 75th percentiles. Differences between $10 \mathrm{mg} / \mathrm{ml}$ oxidized $\mathrm{Hb}$ vs. control, $5 \mathrm{mg} / \mathrm{ml}$ oxidized $\mathrm{Hb}$ vs. control, and $10 \mathrm{mg} / \mathrm{ml} \mathrm{oxidized} \mathrm{Hb}$ vs $5 \mathrm{mg} / \mathrm{ml}$ oxidized $\mathrm{Hb}$ were analyzed using the Kruskal-Wallis test followed by pairwise comparison with significance values adjusted for multiple comparisons. ${ }^{*} P<0.05,{ }^{* *} P<0.01,{ }^{* * *} P<0.001$

\section{NFKB signaling pathway induction by oxidized $\mathrm{Hb}$}

To evaluate if the NFKB signaling pathway might be involved in the pro-inflammatory response observed following exposure to oxidized $\mathrm{Hb}$, a qPCR array targeting NFKB signaling pathway-related genes were analyzed. Results revealed a concentration-dependent upregulation by oxidized $\mathrm{Hb}$ in mRNA levels of activators, transcriptional factors, and pro-inflammatory cytokines associated with the pathway (Fig. 6a). To further evaluate the involvement of the NFKB pathway, mixed glial cells were exposed to oxidized $\mathrm{Hb}$ with or without the simultaneous co-administration of the NFKB activation inhibitor VI benzoxathiole compound. Data indicated that blocking the activation of NFKB reduced the pro-inflammatory induction of CCL2 observed following exposure to oxidized $\mathrm{Hb}$ (Fig. 6b). However, co-administration of the NFKB inhibitor was not observed to reduce the oxidized Hb-induced CCL5 protein secretion (Fig. 6c). The involvement of the NFKB signaling pathway was additionally investigated by analyzing the protein activity of the NFKB transcription factor p65 in mixed glia cells exposed to oxidized $\mathrm{Hb}$. Western blot analysis showed a tendency towards increased level of p65 following exposure to oxidized $\mathrm{Hb}$, both in the cytosolic and the nuclear compartment, which was partly, although not significantly, reduced following co-administration of the NFKB inhibitor (Fig. 6d).

Interestingly, evaluation of a qPCR array targeting apoptosis pathway-related genes, displayed no change in mRNA expression following exposure to oxidized $\mathrm{Hb}$, not even at very high concentrations (e.g., $10 \mathrm{mg} / \mathrm{ml}$ of oxidized $\mathrm{Hb}$, data not shown).

\section{Discussion}

In the present study, we show by exposing mixed glial cells to cell-free $\mathrm{Hb}$-metabolites that oxidized $\mathrm{Hb}$ (constituting a mixture of $\mathrm{Hb}$-metabolites with mainly $\mathrm{Fe}^{3+}$ and some proportion of $\mathrm{Fe}^{4+}$, free heme, and iron) rather than oxyHb $\left(\mathrm{Fe}^{2+}\right)$ is responsible for the proinflammatory and oxidative response observed following IVH. In agreement with previous reports, exposure to hemorrhagic CSF and oxidized $\mathrm{Hb}$ induced cellular activation and pro-inflammatory, oxidative, and cytotoxic pathways [8-13]. Co-administration with $\mathrm{Hp}$ partially reversed the cellular damage induced, both by exposure to hemorrhagic CSF from preterm human infants with GM-IVH and pure oxidized $\mathrm{Hb}$, indicating that oxidation of cell-free oxyHb $\left(\mathrm{Fe}^{2+}\right)$ is a critical step in the damaging pathway of IVH.

Glial cells play an important role in brain developmental processes following birth [19-22]. They act as first responders to neurotoxic agents, thereby protecting against neuronal injury [23-25]. Notwithstanding, there is now mounting evidence supporting a crucial role for negative interactions between glial cells in propagating injury in brain abnormalities [26-28].

Cell-free $\mathrm{Hb}$ is described to be causally involved in the damaging pathway following IVH [2, 10-12]. It has been 

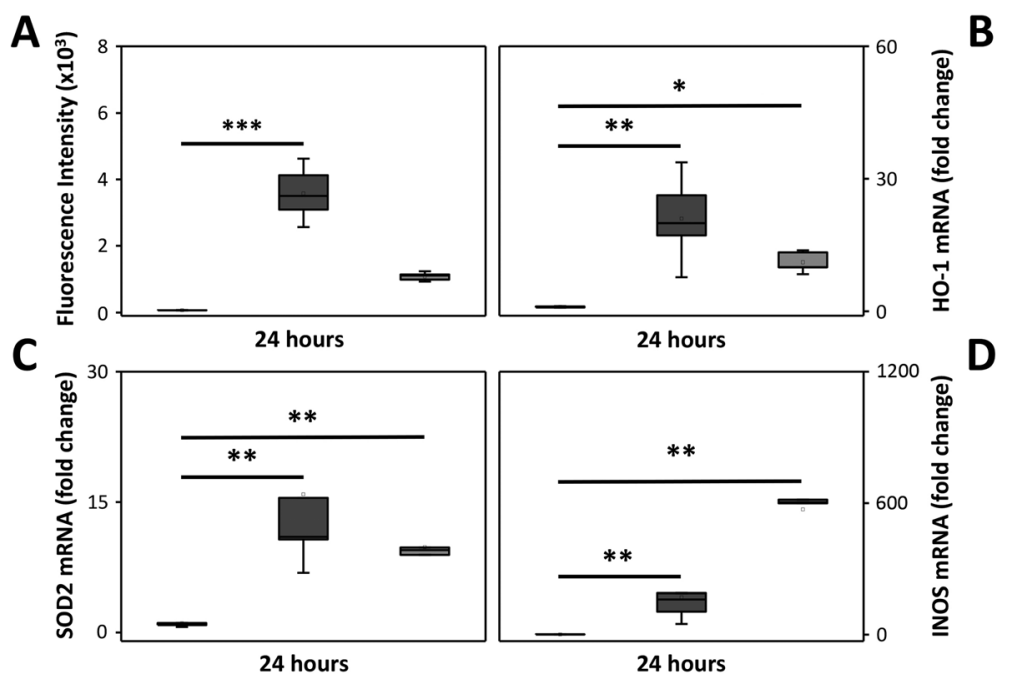

Fig. 5 Effect of $\mathrm{Hp}$ on the damage induced by oxidized $\mathrm{Hb}$. Mixed glial cells were exposed to oxidized $\mathrm{Hb}(10 \mathrm{mg} / \mathrm{ml}$, dark grey bars, $n=6)$ with or without co-administration of $\mathrm{Hp2}-2 / 2-1$ (40 mg/ml, corresponding to a 1:1 molar ratio, light grey bars, $n=6$ ) or culture medium only (control, white bars, $\mathrm{n}$ = 6) for $24 \mathrm{~h}$. Subsequently, ROS production (a), mRNA expression of HO-1 (b), SOD2 (c), and iNOS (d) were analyzed. Results are presented as box plots displaying medians and 25th and 75th percentiles. Differences between oxidized $\mathrm{Hb}$ vs. control and oxidized $\mathrm{Hb}$ with co-administered $\mathrm{Hp}$ vs. control were analyzed using the Kruskal-Wallis test followed by pairwise comparison with significance values adjusted for multiple comparisons. ${ }^{* *} P<0.01$, ${ }^{* * *} P<0.001$

suggested that this is caused by affecting the redox activity of the extracellular environment and thereby exposing cells and tissues to oxidative stress [11, 13, 29, 30]. In addition to its redox-related effects, heme, a cell-free Hb-metabolite has been described to act as a damageassociated molecular pattern molecule, triggering the innate immunity and hence causing pro-inflammatory damage to cells [31-33].

The release of $\mathrm{Hb}$, from red blood cells, and subsequent physical accumulation within the brain was traditionally considered to be the cause of damage to the brain during intracerebral hemorrhage and trauma [34-36]. However, increasing evidence suggests that $\mathrm{Hb}$-related neurotoxicity may rather derive from $\mathrm{Hb}$ breakdown and the generation of downstream metabolites, and not from mere accumulation of the $\mathrm{Hb}$ molecule itself $[37,38]$. The accumulation of metHb, an oxidized form of cell-free $\mathrm{Hb}$ has been reported in other contexts to be cytotoxic. For instance, Kumar et al. reported that cell-free metHb has been found to drive platelets to apoptosis [39]. In malaria, metHb was found, in the presence of heme, to catalyze the formation

Table $1 \mathrm{Hb}$-binding activity of Hp2-2/2-1. Equilibrium constant, association and dissociation constants for the biolayer interferometry experiments. Data expressed as mean \pm SD from three independent experiments

\begin{tabular}{llll}
\hline Hb-metabolite & $\boldsymbol{K}_{\boldsymbol{D}(\mathrm{pM})}$ & $\boldsymbol{k}_{\text {on }}(\mathbf{1} / \mathbf{M s})$ & $\boldsymbol{k}_{\text {dis }}(\mathbf{1} / \mathbf{s})$ \\
\hline $\mathrm{OxyHb}$ & $128.7 \pm 2.0$ & $2.7 \times 10^{5}$ & $3.5 \times 10^{-5}$ \\
$\mathrm{MetHb}$ & $141.4 \pm 1.8$ & $2.0 \times 10^{5}$ & $2.8 \times 10^{-5}$ \\
\hline
\end{tabular}

of a very cytotoxic heme polymer through a single electron transfer mechanism [40].

Here, we exposed a mixed glial cell culture comprised of astrocytes, microglia, and oligodendrocytes to hemorrhagic CSF, obtained by extraction from preterm human infants with GM-IVH, and to pure Hb-metabolites. The concentrations used in this study were guided by the levels of $\mathrm{Hb}$ metabolites previously observed in clinical CSF samples from human preterm infants with IVH [13]. Hemorrhagic $\mathrm{CSF}$, as well as the respective pure $\mathrm{Hb}$-metabolites, was found to induce an upregulation in mRNA expression of the heme sensitive protein, $\mathrm{HO}-1$. However, oxidized $\mathrm{Hb}$ but not oxyHb $\left(\mathrm{Fe}^{2+}\right)$ induced a similar response as hemorrhagic CSF, i.e., a dose-dependent induction of ROS production and pro-inflammatory cytokine mRNA expression and protein secretion, with the rate of ROS production positively correlated with that of pro-inflammatory and oxidative markers.

Congruently, oxidized $\mathrm{Hb}$ caused a disintegration of the polygonal cytoskeletal structure of the glial cells possibly reflecting a metabolic inhibition leading to depletion of energy stores, in addition to upregulation of F-actin proteins in microglial cells, a marker of microglia metamorphosis, motility, activation, and cytokinesis.

This finding is consistent with previously reported data, where cell-free $\mathrm{Hb}$ deposition in the cerebellar white matter, following IVH in the preterm rabbit pup, was associated with activated microgliosis [2]. The upregulation of actin has been suggested to play a key role in the motility and recruitment of microglia to areas of brain inflammation [41]. 


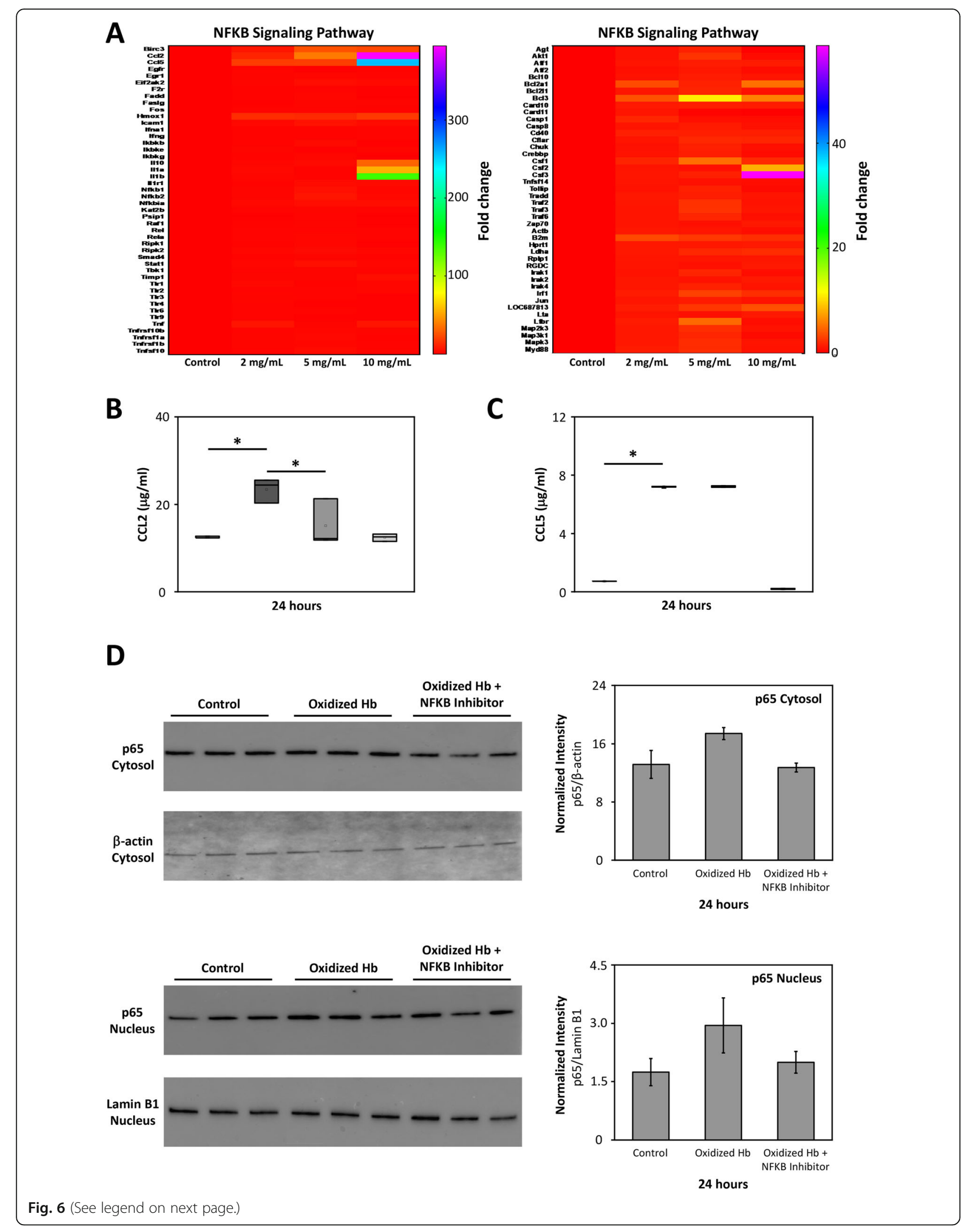




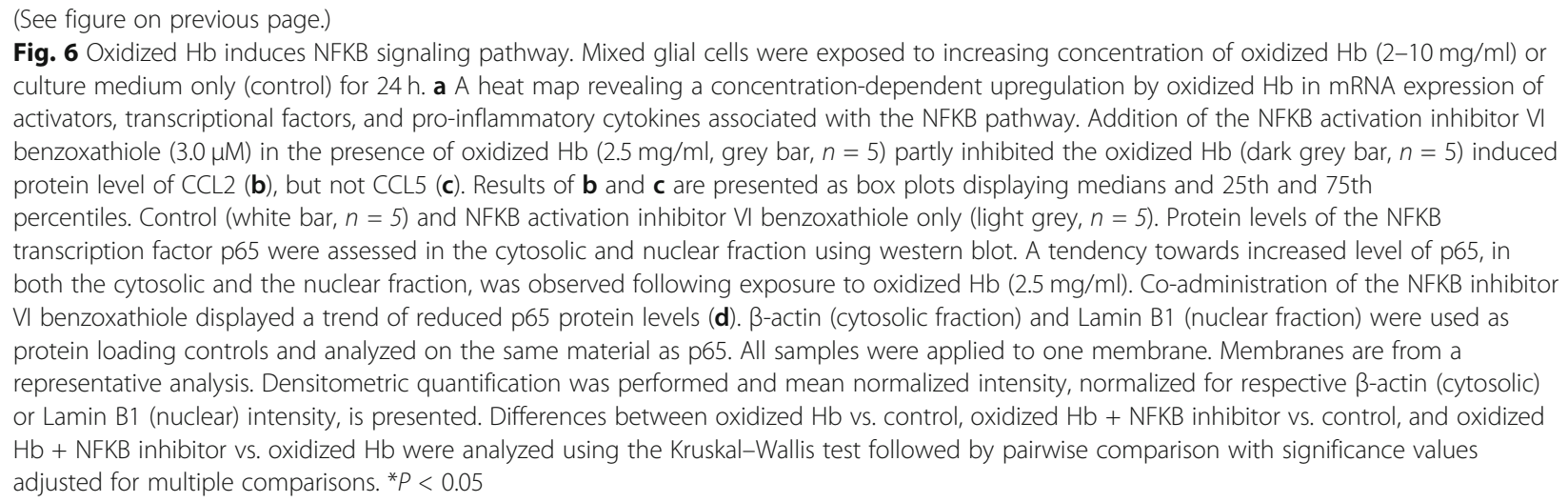

It is worth noting that exposure of the mixed glial cells to heme could only be done at a relatively low concentration $(15 \mu \mathrm{M})$, as compared to oxyHb and oxidized $\mathrm{Hb}$, due to an uncontrollable damaging response by high equivalents of pure heme on the cells.

Although, our understanding of the precise signaling pathways that trigger cell-free Hb-related cell death is still limited, previous studies have hinted on inflammatory necroptosis, apoptosis and/or NFKB modulated inflammation [11, 13, 42].

Here, we show that exposure of the mixed glial cells to oxidized $\mathrm{Hb}$ caused an induction of mRNA expression of several NFKB-related genes as well as protein mediators of the NFKB signaling pathway, specifically the NFKB transcription factor p65. Furthermore, addition of the NFKB inhibitor VI benzoxathiole to the mixed glial culture partly abrogated the aforementioned oxidized $\mathrm{Hb}$ induction.

Interestingly, oxidized $\mathrm{Hb}$ was not found to induce a change in mRNA levels of genes related to the induction of apoptosis pathway. Collectively, this suggests that the observed effects of oxidized $\mathrm{Hb}$ on the mixed glial cells may to some extent be accounted for by activation of the NFKB signaling pathway.

Previous studies have reported a protective effect of $\mathrm{Hp}$, a cell-free $\mathrm{Hb}$ scavenger, following IVH in a preterm rabbit pup model $[2,11]$. In this study, we observed that $\mathrm{Hp}$ to some extent blocked the damaging effects on mixed glial cells, following exposure to hemorrhagic CSF and oxidized $\mathrm{Hb}$. This effect was clearly observed by the significantly reduced production of ROS and the oxidative potential of oxidized $\mathrm{Hb}$. However, $\mathrm{Hp}$ was not found to reverse the induced mRNA expression of iNOS. This finding may suggest a non-ROS-mediated induction of iNOS mRNA expression by oxidized $\mathrm{Hb}$.

We therefore hypothesized that $\mathrm{Hp}$ might bind the oxidized $\mathrm{Hb}$ less effectively. However, using binding studies we could show that the added Hp irreversibly binds strongly with similar affinity to both oxyHb and metHb, which shows that inadequate binding between $\mathrm{Hp}$ and metHb does not explain the partial lack of protection following exposure to oxidized $\mathrm{Hb}$. This observation is consistent with the findings of the study by Kapralov and colleagues, where the cytotoxic effect of cell-free $\mathrm{Hb}$ on macrophages was retained following binding to $\mathrm{Hp}$ in a state of severe inflammation [43]. Furthermore, observations made here, in combination with previous studies, may suggest that $\mathrm{Hp}$ will exert a protective effect so long as there is an equimolar ratio, or surplus, of $\mathrm{Hp}$ to cellfree $\mathrm{Hb}$ [44].

In summary, we found that exposing primary immature rat mixed glial cells to hemorrhagic CSF and oxidized Hb-induced cellular activation and proinflammatory, oxidative, and cytotoxic pathways. To the best of our knowledge, this work is the first in vitro study where a mixed glial cell culture and not singular cellular types has been exposed to a spectrum of cellfree $\mathrm{Hb}$-metabolites.

In this study, $\mathrm{Hp}$ was found to partially reverse the cellular damage induced by hemorrhagic CSF as well as pure oxidized $\mathrm{Hb}$. Collectively, our observations suggest that (i) the conversion of oxyHb $\left(\mathrm{Fe}^{2+}\right)$ to metHb $\left(\mathrm{Fe}^{3+}\right)$ presents a major step for initiation of the damaging pathway following IVH and (ii) Hp may have a protective effect following IVH by decreasing the rate of the spontaneous autoxidation of cell-free $\mathrm{Hb}(\mathrm{Hp}$ binding of oxyHb strongly reduces the ability of the ferrous ion to be oxidized) and by preventing the liberation of heme (through scavenging of cell-free $\mathrm{Hb}$ ). This suggests that treatment with $\mathrm{Hp}$, with the aim of blocking the pro-inflammatory and oxidative effects of cell-free $\mathrm{Hb}$, should be instituted prior to accumulation of oxidized $\mathrm{Hb}$.

\section{Conclusion}

In this study, we show that the conversion of cell-free oxyHb to oxidized $\mathrm{Hb}$ is the initiation step for the damage 
observed following IVH and that the timeline between the conversion from oxyHb $\left(\mathrm{Fe}^{2+}\right)$ to metHb $\left(\mathrm{Fe}^{3+}\right)$ may provide a therapeutic window for implementation of neuroprotective interventions targeting cell-free $\mathrm{Hb}$.

\section{Supplementary Information}

The online version contains supplementary material available at https:/doi. org/10.1186/s12974-020-02052-4

Additional file 1. Hb-binding activity of $\mathrm{Hp}$.

Additional file 2. Additional File Legends.

\section{Abbreviations}

BSA: Bovine serum albumin; CCL2: Chemokine (c-c motif) ligand 2; CCL5: Chemokine (C-C motif) ligand 5; CSF: Cerebrospinal fluid; DCF: 2',7'dichloro fluorescein; DMEM: Dulbecco's modified eagle medium; FBS: Fetal bovine serum; GAPDH: Glyceraldehyde-3-phosphate dehydrogenase; GMIVH: Germinal matrix intraventricular hemorrhage; Hb: Hemoglobin; HBSS: Hank's balanced salt solution; HO-1: Heme oxygenase 1; Hp: Haptoglobin; Iba1: Ionized calcium-binding adaptor molecule 1; ICC: Immunocytochemistry; iNOS: Inducible nitric oxide synthase; MetHb: Methemoglobin, ferric hemoglobin; NFKB: Nuclear factor kappa beta; OxyHb: Oxyhemoglobin, ferrous hemoglobin; PFA: Paraformaldehyde; PBS: Phosphate-buffer saline; ROS: Reactive oxygen species; SOD2: Superoxide dismutase 2; TNFa: Tumor necrosis factor alpha

\section{Acknowledgements}

The authors wish to acknowledge Susanne Grönlund and Helena Karlsson for outstanding technical assistance. The authors wish to acknowledge the Erasmus Mundus Joint Doctorate in Fetal and Perinatal Medicine (Fetalmed-PhD).

\section{Authors' contributions}

AA, SVK, DL, and MG designed the study. AA, SVK, NB, TG, MI, NO, BH, DL, and $M G$ conducted the study, acquired, analyzed, and interpreted the data. $A A, D L$, and $M G$ drafted the manuscript and $A A, S V K, N B, T G, M I, N O, B H, D L$, and MG finally approved the content of this manuscript and are consequently in agreement to be accountable for all aspects of this work.

\section{Funding}

This work was supported by the Swedish Research Council (2017-02112), governmental ALF research grants to Lund University and Lund University Hospital, the Crafoordska Foundation, the Swedish Foundation for Strategic Research, the Greta and Johan Kock Foundation, and the Alfred Österlund Foundation. Open Access funding provided by Lund University.

\section{Availability of data and materials}

The datasets used and/or analyzed during the current study are available from the corresponding author on reasonable request.

\section{Ethics approval and consent to participate}

This study was approved by the ethical committee review board for studies in human subjects at Lund University, Lund, Sweden, and the Swedish Animal Ethics Committee in Lund, Sweden.

\section{Consent for publication}

Not applicable.

\section{Competing interests}

NB and TG are employed by CSL Behring. This does not present any conflict of interest.

The authors AA, SVK, MI, NO, BH, DL, and MG declare that they have no competing interests.

\section{Author details}

${ }^{1}$ Lund University, Department of Clinical Sciences Lund, Pediatrics, Lund, Sweden. ${ }^{2}$ R\&D, CSL Behring, Kankakee, IL, USA. ${ }^{3}$ Research Bern, CSL Behring, Bern, Switzerland. ${ }^{4}$ Fetal i+D Fetal Medicine Research Center, BCNatal-Barcelona Center for Maternal-Fetal and Neonatal Medicine (Hospital
Clínic and Hospital Sant Joan de Deu), Institut Clínic de Ginecologia, Obstetricia i Neonatologia, Universitat de Barcelona, Barcelona, Spain. ${ }^{5}$ ImaGene-iT AB, Medicon Village, Lund, Sweden.

Received: 22 May 2020 Accepted: 9 December 2020

Published online: 11 February 2021

\section{References}

1. Ballabh P. Intraventricular hemorrhage in premature infants: mechanism of disease. Pediatr Res. 2010;67:1-8.

2. Agyemang AA, Sveinsdóttir K, Vallius S, Sveinsdóttir S, Bruschettini M, Romantsik O, et al. Cerebellar exposure to cell-free hemoglobin following preterm intraventricular hemorrhage: causal in cerebellar damage? Transl Stroke Res. 2017:8(5):461.

3. Ley D, Romantsik O, Vallius S, Sveinsdóttir K, Sveinsdóttir S, Agyemang AA, et al. High presence of extracellular hemoglobin in the periventricular white matter following preterm intraventricular hemorrhage. Front Physiol. 2016;7:330.

4. Lee JY, Keep RF, He Y, Sagher O, Hua Y, Xi G. Hemoglobin and iron handling in brain after subarachnoid hemorrhage and the effect of deferoxamine on early brain injury. J Cereb Blood Flow Metab. 2010;30:1793-803.

5. Lok J, Leung W, Murphy S, Butler W, Noviski N, Lo EH. Intracranial hemorrhage: mechanisms of secondary brain injury. Acta Neurochir Suppl. 2011;111:63-9.

6. Kumar S, Bandyopadhyay U. Free heme toxicity and its detoxification systems in human. Toxicol Lett. 2005;157:175-88.

7. Quaye IK. Extracellular hemoglobin: the case of a friend turned foe. Front Physiol. 2015;6:96

8. Nosarti C, Giouroukou E, Micali N, Rifkin L, Morris RG, Murray RM. Impaired executive functioning in young adults born very preterm. J Int Neuropsychol Soc. 2007;13:571-81.

9. Indredavik MS, Vik T, Evensen KA, Skranes J, Taraldsen G, Brubakk AM. Perinatal risk and psychiatric outcome in adolescents born preterm with very low birth weight or term small for gestational age. J Dev Behav Pediatr. 2010;31:286-94.

10. Sveinsdóttir S, Gram M, Cinthio M, Sveinsdóttir K, Mörgelin M, Ley D. Altered expression of aquaporin 1 and 5 in the choroid plexus following preterm intraventricular hemorrhage. Dev Neurosci. 2014;36:542-51.

11. Gram M, Sveinsdóttir S, Cinthio M, Sveinsdóttir K, Hansson SR, Mörgelin M, et al. Extracellular hemoglobin - mediator of inflammation and cell death in the choroid plexus following preterm intraventricular hemorrhage. J Neuroinflammation. 2014;11:200.

12. Smeds E, Romantsik O, Jungner Å, Erlandsson L, Gram M. Pathophysiology of extracellular haemoglobin: use of animal models to translate molecular mechanisms into clinical significance. ISBT Science Series. 2017;12:134-41.

13. Gram M, Sveinsdóttir S, Ruscher K, Hansson SR, Cinthio M, Åkerström B, et al. Hemoglobin induces inflammation after preterm intraventricular hemorrhage by methemoglobin formation. J Neuroinflammation. 2013; 10:100

14. Amri F, Ghouili I, Tonon MC, Amri M, Masmoudi-Kouki O. Hemoglobinimproved protection in cultured cerebral cortical astroglial cells: inhibition of oxidative stress and caspase activation. Front Endocrinol (Lausanne). 2017:8:67.

15. Sankar SB, Donegan RK, Shah KJ, Reddi AR, Wood LB. Heme and hemoglobin suppress amyloid beta-mediated inflammatory activation of mouse astrocytes. J Biol Chem. 2018;293:11358-73.

16. Lin S, Yin Q, Zhong Q, LV FL, Zhou Y, Li JQ, et al. Heme activates TLR4mediated inflammatory injury via MyD88/TRIF signaling pathway in intracerebral hemorrhage. J Neuroinflammation. 2012;9:46.

17. Lara FA, Kahn SA, da Fonseca AC, Bahia CP, Pinho JP, Graca-Souza AV, et al. On the fate of extracellular hemoglobin and heme in brain. J Cereb Blood Flow Metab. 2009;29:1109-20.

18. Winterbourn CC. Oxidative reactions of hemoglobin. Methods Enzymol. 1990;186:265-72.

19. Lindsey BW, Hall ZJ, Heuze A, Joly JS, Tropepe V, Kaslin J. The role of neuroepithelial-like and radial-glial stem and progenitor cells in development, plasticity, and repair. Prog Neurobiol. 2018;170:99-114.

20. Trébuchet G, Giangrande A. Glial cells in neural development. In eLS: John Wiley \& Sons Itd; 2012

21. Reemst K, Noctor SC, Lucassen PJ, Hol EM. The indispensable roles of microglia and astrocytes during brain development. Front Hum Neurosci. 2016;10:566. 
22. Jäkel S, Dimou L. Glial cells and their function in the adult brain: a journey through the history of their ablation. Front Cell Neurosci. 2017;11:24.

23. Burda JE, Bernstein AM, Sofroniew MV. Astrocyte roles in traumatic brain injury. Exp Neurol. 2016;275(Pt 3):305-15.

24. Bylicky MA, Mueller GP, Day RM. Mechanisms of endogenous neuroprotective effects of astrocytes in brain injury. Oxidative Med Cell Longev. 2018;2018:6501031.

25. Donat CK, Scott G, Gentleman SM, Sastre M. Microglial activation in traumatic brain injury. Front Aging Neurosci. 2017;9:208.

26. Kirkley KS, Popichak KA, Afzali MF, Legare ME, Tjalkens RB. Microglia amplify inflammatory activation of astrocytes in manganese neurotoxicity. J Neuroinflammation. 2017;14:99

27. Jha MK, Jo M, Kim JH, Suk K. Microglia-astrocyte crosstalk: an intimate molecular conversation. Neuroscientist. 2018;25(3):227.

28. Matias D, Balca-Silva J, da Graca GC, Wanjiru CM, Macharia LW, Nascimento CP. et al. Microglia/astrocytes-glioblastoma crosstalk: crucial molecular mechanisms and microenvironmental factors. Front Cell Neurosci. 2018;12:235.

29. Reeder BJ. The redox activity of hemoglobins: from physiologic functions to pathologic mechanisms. Antioxid Redox Signal. 2010;13:1087-123.

30. Schaer DJ, Buehler PW, Alayash Al, Belcher JD, Vercellotti GM. Hemolysis and free hemoglobin revisited: exploring hemoglobin and hemin scavengers as a novel class of therapeutic proteins. Blood. 2013;121:1276-84.

31. Lee SK, Ding JL. A perspective on the role of extracellular hemoglobin on the innate immune system. DNA Cell Biol. 2013;32:36-40.

32. Gladwin MT, Ofori-Acquah SF. Erythroid DAMPs drive inflammation in SCD Blood. 2014;123:3689-90

33. Wang YC, Zhou Y, Fang H, Lin S, Wang PF, Xiong RP, et al. Toll-like receptor 2/4 heterodimer mediates inflammatory injury in intracerebral hemorrhage. Ann Neurol. 2014;75:876-89.

34. Zhou Y, Wang Y, Wang J, Anne Stetler R, Yang QW. Inflammation in intracerebral hemorrhage: from mechanisms to clinical translation. Prog Neurobiol. 2014;115:25-44.

35. Laird MD, Wakade C, Alleyne CH Jr, Dhandapani KM. Hemin-induced necroptosis involves glutathione depletion in mouse astrocytes. Free Radic Biol Med. 2008;45:1103-14.

36. Jaremko KM, Chen-Roetling J, Chen L, Regan RF. Accelerated hemolysis and neurotoxicity in neuron-glia-blood clot co-cultures. J Neurochem. 2010;114: 1063-73.

37. Vanderveldt GM, Regan RF. The neurotoxic effect of sickle cell hemoglobin. Free Radic Res. 2004;38:431-7.

38. Bishop GM, Robinson SR. Quantitative analysis of cell death and ferritin expression in response to cortical iron: implications for hypoxia-ischemia and stroke. Brain Res. 2001;907:175-87.

39. NaveenKumar SK, Hemshekhar M, Sundaram MS, Kemparaju K, Girish KS Cell-free methemoglobin drives platelets to apoptosis via mitochondrial ROS-mediated activation of JNK and p38 MAP kinase. Biochem Biophys Res Commun. 2017:491:183-91.

40. Deshmukh $\mathrm{R}$, Trivedi V. Pro-stimulatory role of methemoglobin in inflammation through hemin oxidation and polymerization. Inflamm Allergy Drug Targets. 2013;12:68-78.

41. Abd-El-Basset EM, Prashanth J, Ananth Lakshmi KV. Up-regulation of cytoskeletal proteins in activated microglia. Med Princ Pract. 2004;13:325-33.

42. Majmundar N, Kim B, Prestigiacomo CJ. Necroptosis pathway in treatment of intracerebral hemorrhage: novel therapeutic target. World Neurosurg. 2016;89:716-7.

43. Kapralov A, Vlasova FW II, Maeda A, Walson K, Tyurin VA, Huang Z, et al. Peroxidase activity of hemoglobin-haptoglobin complexes: covalent aggregation and oxidative stress in plasma and macrophages. J Biol Chem. 2009;284:30395-407.

44. Deuel JW, Vallelian F, Schaer CA, Puglia M, Buehler PW, Schaer DJ. Different target specificities of haptoglobin and hemopexin define a sequential protection system against vascular hemoglobin toxicity. Free Radic Biol Med. 2015;89:931-43.

\section{Publisher's Note}

Springer Nature remains neutral with regard to jurisdictional claims in published maps and institutional affiliations.

\section{Ready to submit your research? Choose BMC and benefit from:}

- fast, convenient online submission

- thorough peer review by experienced researchers in your field

- rapid publication on acceptance

- support for research data, including large and complex data types

- gold Open Access which fosters wider collaboration and increased citations

- maximum visibility for your research: over $100 \mathrm{M}$ website views per year

At BMC, research is always in progress.

Learn more biomedcentral.com/submissions 